\title{
History does not Repeat Itself, but it Rhymes ${ }^{1}$
}

\author{
Ken Pease* \\ Criminology and Social Sciences, University of Derby, England
}

Submission: June 05, 2019; Published: July 19, 2019

"Corresponding author: Ken Pease, Criminology and Social Sciences, College of Business, Law and Social Sciences, University of Derby, England

\begin{abstract}
Research dating from the 1990s demonstrates the extent to which high crime rates are attributable to repeated victimisation of the same individuals rather than to the proportion of people, households or businesses victimised. The practical application of these findings to crime reduction has been disappointingly meagre. A major reason for this is that police data systems are offender and event focused, so that victim 'careers' are obscured.
\end{abstract}

Keywords: History; Households; Crime

\section{Opinion}

The meaning of the title of this note is perhaps somewhat obscure, though memorable. It denotes the extent to which crime at a time and place is predictable in all or some aspects from previous crime at and around the same place and similar times and against the same victims. It is argued here that the extent to which repeat and near repeat victimisation informs policing practice is disappointingly meagre, and that the conventional organisations of police data systems is a major reason for the failure to incorporate the lessons of the relevant research in practice.

In the 1990s, a raft of research findings demonstrated the extent to which crime victimisation was concentrated at the individual person or household level, indeed that high crime areas were characterised more by the extent of repeat victimisation (victimisations per victim) rather than the proportion of people or households victimised (victims per person or household available to be victimised) [1]. This was thought by many, including the present writer, to be a conclusion of substantial theoretical and practical importance. Hot spot policing, in which police and other resources are directed to localities with high rates of victimisation are to be applauded but offer unnecessarily limited precision in anticipated where, when and to whom crime will occur.

Hot spot areas encompass individual people and households with varied risk of victimisation. Policing at the most disaggregated level, which we can describe as hot dot policing, matches resources to risk more precisely. The available research strongly suggests that crime reduction efforts are best focused on preventing repeat and near repeat crimes, perhaps by improving security measures around the vulnerable, and predictive police patrolling. Two decades on from the publication of the bulk of relevant research, the notion of hot dot policing has not been practised widely, despite its advantages in crime control.

Pease [2] identified several reasons why the extent of repeat and near repeat victimisation has not been recognised. These included

a) Police work was fragmented so that officers do not get the continuity of experience which allows them to see the extent of repeat victimisation.

b) Research tends to look at restricted time windows. The shorter the window, the more repeat victimisation will be understated.

c) Chronic victims report crime against them less.

d) The organisation of police data obscures the extent of repeat victimisation.

Nearly thirty years after the publication of the work which signposted the reduction of repeat victimisation as a promising mode of crime prevention, its translation into police work has been limited. The writer has analysed many sets of police data over the three decades and it remains the case that the way police data are organised still obscures the extent of repeats and near repeats. The punchline of this short note is that police data systems are the primary obstacle to the recognition of repeat victimisation. Put simply, the police can readily trace the criminal careers of offenders ('nominals' in the UK jargon) [3].

They can identify crime patterns by time, area and type of offence. However, looking at victim careers, i.e. the victimisation history of individual people and households, requires much 


\section{Annals of Social Sciences \& Management studies}

work on the part of crime analysts or academic researchers. In conclusion, the failure of repeat victimisation to gain substantial traction in the crime reduction enterprise can be substantially ascribed to the offender and event focus of police data. A fundamental revision of police data to become victim focused will be necessary before police officers are in a position to get the most from data about the extent to which, as the title puts it "History does not repeat itself. but it rhymes."

\section{References}

1. Trickett Alan, Denise R Osborn, Julie Seymour, Ken Pease (1992) What is Different About High Crime Areas? British Journal of Criminology 32(1): 81-89.

2. Pease K (1998) Repeat Victimisation: Taking Stock. Home Office, London.

3. Pease Ken, Ignatans Dainis, Batty Lauren (2018) Whatever Happened to Repeat Victimisation? Crime Prevention and Community Safety 20(4): 256-267.

This work is licensed under Creative Commons Attribution 4.0 License DOI:_10.19080/ASM.2019.03.555623 